\title{
Effect of gravity wave temperature fluctuations on homogeneous ice nucleation in the tropical tropopause layer
}

\author{
T. Dinh ${ }^{1}$, A. Podglajen ${ }^{2}$, A. Hertzog ${ }^{2}$, B. Legras ${ }^{3}$, and R. Plougonven ${ }^{2}$ \\ ${ }^{1}$ Program in Atmospheric and Oceanic Sciences, Princeton University, Princeton, New Jersey, USA \\ ${ }^{2}$ Laboratoire de Météorologie Dynamique, École Polytechnique, Palaiseau, France \\ ${ }^{3}$ Laboratoire de Météorologie Dynamique, École Normale Supérieure, Paris, France \\ Correspondence to: T. Dinh (tdinh@princeton.edu)
}

Received: 3 March 2015 - Published in Atmos. Chem. Phys. Discuss.: 24 March 2015

Revised: 5 November 2015 - Accepted: 24 November 2015 - Published: 14 January 2016

\begin{abstract}
The impact of high-frequency fluctuations of temperature on homogeneous nucleation of ice crystals in the vicinity of the tropical tropopause is investigated using a bin microphysics scheme for air parcels. The imposed temperature fluctuations come from measurements during isopycnic balloon flights near the tropical tropopause. The balloons collected data at high frequency, guaranteeing that gravity wave signals are well resolved.

With the observed temperature time series, the numerical simulations with homogeneous freezing show a full range of ice number concentration (INC) as previously observed in the tropical upper troposphere. In particular, a low INC may be obtained if the gravity wave perturbations produce a non-persistent cooling rate (even with large magnitude) such that the absolute change in temperature remains small during nucleation. This result is explained analytically by a dependence of the INC on the absolute drop in temperature (and not on the cooling rate). This work suggests that homogeneous ice nucleation is not necessarily inconsistent with observations of low INCs.
\end{abstract}

\section{Introduction}

Cirrus clouds have an important impact on the global radiative energy budget (Lohmann and Roeckner, 1995). In the tropical tropopause layer (TTL; Fueglistaler et al., 2009), cirrus clouds contribute to the radiative heating (Corti et al., 2006; Dinh and Fueglistaler, 2014a) and control the dehydration of the air before entry into the stratosphere (Brewer, 1949; Jensen et al., 1996; Dinh and Fueglistaler, 2014b). For all cirrus clouds, the radiative and climate impact, ability to modify water vapour, and cloud evolution are sensitive to the ice number concentration (e.g. Kärcher et al., 2014), which depends strongly on the nucleation process of ice crystals.

When evaluating the ice number concentration (INC) produced by nucleation, it has been often assumed that the relevant timescale is sufficiently short such that the vertical velocity and associated adiabatic cooling rate remain constant (e.g. Barahona and Nenes, 2008). For constant cooling rates, homogeneous freezing of aqueous aerosols produces higher INCs $\left(>1000 \mathrm{~L}^{-1}\right)$ than those commonly observed $\left(\lesssim 100 \mathrm{~L}^{-1}\right)$ in cirrus clouds (Lawson et al., 2008; Krämer et al., 2009; Davis et al., 2010). Observations and calculations of INC based on homogeneous freezing can be reconciled only if very low vertical speeds $\left(w<0.01 \mathrm{~m} \mathrm{~s}^{-1}\right)$ are used in the simulations. This seems at odds with the ubiquitous presence of atmospheric gravity waves, which typically generate disturbances an order of magnitude larger in the vertical velocity. Therefore, it has been suggested that heterogeneous freezing (instead of homogeneous freezing) is the dominant nucleation mechanism for cirrus clouds in the upper troposphere (Jensen et al., 2010, 2012). The INC obtained by heterogeneous freezing is apparently limited by the availability of suitable ice nuclei (generally less than $100 \mathrm{~L}^{-1}$ ) in the upper troposphere (Chen et al., 1998; Rogers et al., 1998).

However, Spichtinger and Krämer (2013) pointed out that high-frequency variations in temperature and cooling rates can substantially decrease the INC produced during homogeneous nucleation compared to those obtained with constant updraft speeds. However, their numerical results are based 
on ideally constructed temperature time series and so remain somewhat conceptual. The present work complements their study by using temperature time series data collected at high temporal resolution during long-duration balloon flights near the tropical tropopause. The observed temperatures contain perturbations from a spectrum of atmospheric waves, with periods ranging from days to minutes. Our numerical simulations based on these observed temperature time series confirm the earlier results of Spichtinger and Krämer (2013).

In addition to the numerical simulations using realistic temperature time series (as described above), our contribution is to provide a theoretical framework for characterising homogeneous nucleation while taking into account the temperature fluctuations due to gravity waves. The theoretical framework put forward here complements previous studies (see also Barahona and Nenes, 2011; Jensen et al., 2010, 2012; Murphy, 2014), where the effect of high-frequency temperature fluctuations on ice nucleation has been described but not explained analytically.

The article is organised as follows. Sections 2 and 3 describe the balloon data and the technical details of the model used here to simulate homogeneous ice nucleation. Section 4 presents the numerical results. Section 5 provides the theoretical basis explaining how the fluctuations in time of temperature may affect homogeneous ice nucleation. Section 6 contains the conclusions.

\section{Balloon data descriptions}

The temperature time series used in this study are derived from data collected by two long-duration, superpressure balloons launched by the French Space Agency from Seychelles Islands $\left(55.5^{\circ} \mathrm{E}, 4.6^{\circ} \mathrm{N}\right)$ in February 2010 in the framework of the pre-Concordiasi campaign (Rabier et al., 2010). The balloons flew at an altitude of about $19 \mathrm{~km}$ and achieved circumterrestrial flights, therefore sampling the whole equatorial circle. Details on the balloon trajectories and largescale atmospheric dynamics during the flights can be found in Podglajen et al. (2014). Superpressure balloons are advected by the wind on isopycnic (constant-density) surfaces and therefore behave as quasi-Lagrangian tracers of atmospheric motions. A further remarkable property of superpressure balloons is their sensitivity to atmospheric gravity waves (Massman, 1978; Nastrom, 1980; Boccara et al., 2008; Vincent and Hertzog, 2014). The sampling frequency of the balloon position, atmospheric pressure, and temperature during the campaign is every $30 \mathrm{~s}$.

Here, we do not use the temperature observations gathered during the flights to constrain the nucleation simulations; these time series tend to be both too noisy and warm biased during daytime. Instead, we infer the temperature disturbances from the balloon vertical displacements $\left(\zeta_{\mathrm{b}}^{\prime}\right)$. The isentropic air parcel vertical displacement $\left(\zeta^{\prime}\right)$ is linked to that of the isopycnic balloon through

$\zeta^{\prime}=\frac{g / c_{p}+\partial \bar{T} / \partial z}{g / R_{\mathrm{a}}+\partial \bar{T} / \partial z} \zeta_{\mathrm{b}}^{\prime}$

(Boccara et al., 2008), where $g$ is the gravitational acceleration, $c_{p}$ is the specific heat at constant pressure, $R_{\mathrm{a}}$ is the gas constant for air, and $\partial \bar{T} / \partial z$ is the vertical gradient of the background temperature. We use the European Centre for Medium-range Weather Forecasts (ECMWF) operational analyses to diagnose $\partial \bar{T} / \partial z$ at the balloon position in the above equation. The isentropic vertical displacement is then converted to the Lagrangian temperature fluctuation (felt by the air parcel) at the balloon flight level (i.e. in the lower stratosphere) by

$T_{\mathrm{LS}}^{\prime}=-\frac{g}{c_{p}} \zeta^{\prime}$.

We must furthermore take into account that the balloons flew in the lower stratosphere rather than in the upper troposphere where most of the cirrus form. Because of the difference in stability of these two regions, the vertical displacements and hence temperature fluctuations induced by gravity waves are larger in the upper troposphere than in the lower stratosphere. For conservative wave propagation, it can be shown that

$T_{\mathrm{UT}}^{\prime}=\sqrt{\frac{N_{\mathrm{LS}}}{N_{\mathrm{UT}}}} \exp \left(-\frac{\Delta z}{2 H}\right) T_{\mathrm{LS}}^{\prime}$,

where $N_{\mathrm{UT}}$ and $N_{\mathrm{LS}}$ respectively are the buoyancy frequencies in the upper troposphere and lower stratosphere, $\Delta z$ is the difference between the balloon flight and cloud altitudes, $H$ is the atmospheric scale height ( $\sim 6 \mathrm{~km}$ in the TTL), and $T_{\mathrm{UT}}^{\prime}$ is the temperature disturbance in the upper troposphere induced by the gravity wave packet observed at the balloon altitude. Typically, $N_{\mathrm{LS}} \sim 2 N_{\mathrm{UT}}$, and $T_{\mathrm{UT}}^{\prime} \sim T_{\mathrm{LS}}^{\prime}$ if the cirrus forms $4 \mathrm{~km}$ below the balloon flight level.

The power spectrum of the temperature perturbation $\left(T_{\mathrm{UT}}^{\prime}\right)$ time series derived from the balloon vertical displacements is shown in Fig. 1. Notice that the balloon neutral oscillations due to the flight mechanics have a frequency of $0.25 \mathrm{~min}^{-1}$. Since the spectrum of gravity waves extends up to the BruntVäisälä frequency (typically less than $0.20 \mathrm{~min}^{-1}$ in the TTL), we expect that the balloon motions do not negatively affect the quality of gravity waves in the data set. Nevertheless, we applied a Butterworth band-stop filter to remove the balloon oscillations from the temperature time series (Fig. 1). We have also experimented filtering the data using a high cutoff frequency of 0.10 or $0.20 \mathrm{~min}^{-1}$ (not shown). Our results (Sect. 4) are not sensitive to the data filtering method.

\section{Model configurations}

We compute homogeneous freezing of aqueous aerosols following Koop et al. (2000) and depositional growth of ice 


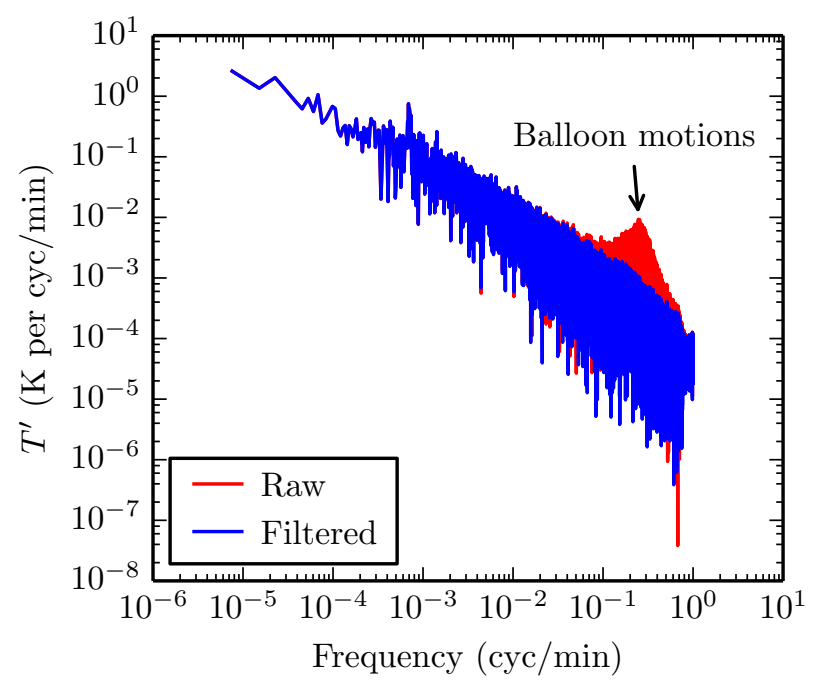

Figure 1. Power spectrum of the raw and filtered temperature perturbation time series derived from the balloon vertical displacements.

crystals (see e.g. Pruppacher and Klett, 1978) using the bin scheme designed by Dinh and Durran (2012). The formula for the water activity has been revised following Koop and Zobrist (2009). The saturation water vapour pressure (over ice) is taken from Murphy and Koop (2005).

Ice crystals and aerosol particles that form ice crystals are assumed to be spherical. We use 20 bins to resolve the size distribution of ice crystals with radii up to $10 \mu \mathrm{m}$. The time step used in the simulations is $0.5 \mathrm{~s}$. The numerical results do not change with more bins or smaller time step, i.e. the stated bin and time resolutions are sufficient to ensure accuracy.

The number concentration of the aerosol reservoir is $N_{\mathrm{a}}=$ $200 \mathrm{~cm}^{-3}$, and aerosol particles are assumed to be monodispersed in size with a radius of $0.25 \mu \mathrm{m}$. These assumptions are within observed properties of aerosols in the upper troposphere (Chen et al., 1998; Hermann et al., 2003). Simulations with polydispersed aerosols up to $1 \mu \mathrm{m}$ in size do not show qualitative differences, and so we retain a monodispersed distribution to simplify the analytical derivation in Sect. 5.

In addition, we do not consider ice sedimentation in order to focus solely on the nucleation process. Further, nucleation is calculated only for initially ice-free air parcels. The effect of pre-existing ice on nucleation has been discussed elsewhere (see Shi et al., 2015).

Currently, there is not yet a well-constrained limit on the deposition coefficient (also called accommodation coefficient). The deposition coefficient controls the number of gas molecules that effectively enter the condensed phase after a collision with the ice surface. Laboratory measurements of the deposition coefficient vary by as much as 3 orders of magnitude, between 0.001 and 1 (Magee et al., 2006; Skrotzki et al., 2013). Figure 2 illustrates the effect of varying the deposition coefficient $\alpha$ on the INC calculated using

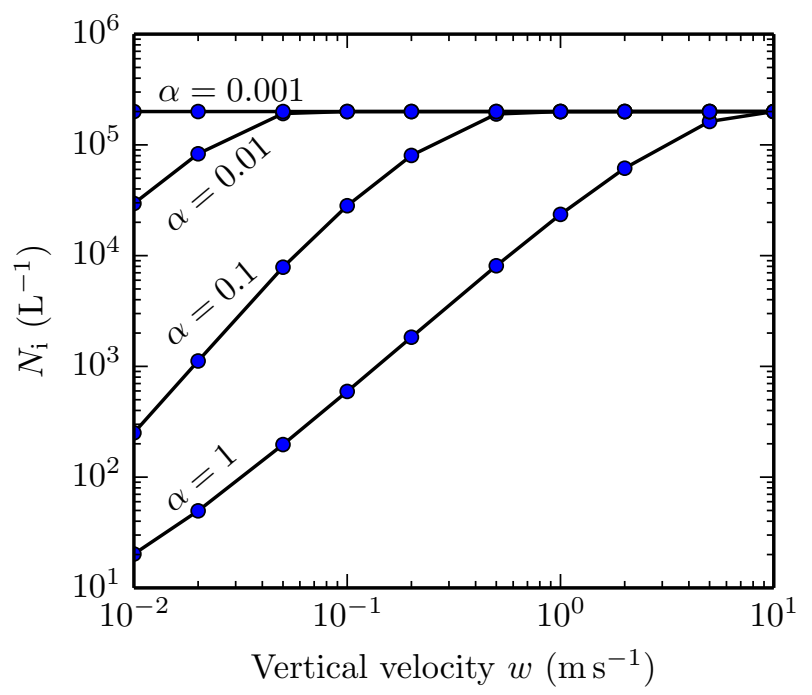

Figure 2. INC obtained from homogeneous nucleation at $195 \mathrm{~K}$ forced by constant vertical velocity $w$ for different values of the deposition coefficient $\alpha$.

our model. For the same constant updraft, the INC obtained by homogeneous nucleation is smaller for larger $\alpha$. In the following sections, we first present the simulations for $\alpha=0.1$ and then discuss the sensitivity to $\alpha$ in Sects. 4.3.3 and 5.2.

\section{Numerical simulations}

For adiabatic motions, the effect of pressure variations on the water vapour mixing ratio $(r)$ can be neglected compared with that due to temperature variations. Assuming constant air pressure, we prescribe an initial water vapour content for the air parcels such that nucleation occurs at a chosen temperature $T_{0}$. This is possible because the saturation ratio with respect to ice $(S)$ at the threshold of nucleation $\left(S_{\text {nuc }}\right)$ is a function of temperature (Koop et al., 2000; Kärcher and Lohmann, 2002; Ren and Mackenzie, 2005), and it is related to the initial water vapour mixing ratio of air parcels by

$r_{0}=\frac{e_{\mathrm{sat}}\left(T_{0}\right) S_{\mathrm{nuc}}\left(T_{0}\right)}{p} \frac{R_{\mathrm{a}}}{R_{\mathrm{v}}}$,

where $p$ is air pressure, $e_{\mathrm{sat}}$ is the saturation water vapour pressure over ice, and $R_{\mathrm{a}}$ and $R_{\mathrm{v}}$ are respectively the gas constants of air and water vapour. The notations $e_{\text {sat }}\left(T_{0}\right)$ and $S_{\text {nuc }}\left(T_{0}\right) \equiv S_{0}$ refer to respectively $e_{\text {sat }}$ and $S_{\text {nuc }}$ at $T_{0}$. Note that up to the nucleation time the vapour mixing ratio $r$ is conserved $\left(r=r_{0}\right.$ for $\left.t \leq t_{0}\right)$. As illustrated in Fig. 3, every air parcel follows an isoline of constant water vapour mixing ratio $\left(r=r_{0}\right)$ until crossing the $S_{\text {nuc }}(T)$ curve, at which point $\left(t=t_{0}\right)$ nucleation begins.

The simulations were first carried out for pressure $p=$ $100 \mathrm{hPa}$, nucleation temperature $T_{0}=195 \mathrm{~K}$, and deposition coefficient $\alpha=0.1$ (Sect. 4.1, 4.2, and 4.3.1). A nucleation 


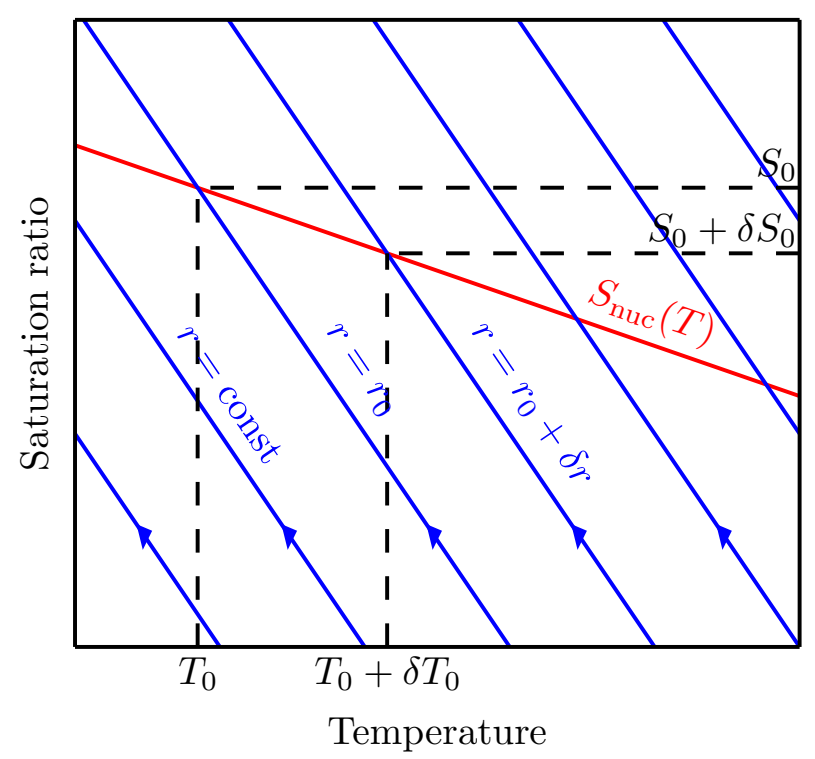

Figure 3. Diagram illustrating the initial conditions of the air parcels. Prior to nucleation air parcels follow isolines of water vapour mixing ratio $r$ (shown here in blue) and approach the curve $S_{\text {nuc }}(T)$ from below (as indicated by the arrows). Nucleation begins at the intersections of the $r$ isolines with the curve $S_{\text {nuc }}(T)$.

event may be formally defined to start when the rate of nucleation $J$ exceeds a threshold $J_{\varepsilon}\left(J \geq J_{\varepsilon}\right)$ and to end when it becomes less than $J_{\varepsilon}\left(J<J_{\varepsilon}\right)$. For our simulations, choosing a threshold of $J_{\varepsilon}=10^{9} \mathrm{~L}^{-1} \mathrm{~s}^{-1}$, we have $S_{0}=1.553$ for $T_{0}=195 \mathrm{~K}$. Sensitivities to nucleation temperature $T_{0}$ in the range between 180 and $210 \mathrm{~K}$ and $\alpha$ in the range between 0.001 and 1 are discussed in Sect. 4.3.2 and 4.3.3. Time series of temperature is defined by

$T(t)=\bar{T}+T^{\prime}(t)$

where $T^{\prime}(t)$ are either idealised following temperature variations associated with constant and time-varying vertical velocities (Sect. 4.1 and 4.2), or taken from the balloon data (Sect. 4.3). The base temperature $\bar{T}$ is varied between 180 and $220 \mathrm{~K}$, which allows us to explore a range of saturation ratio with respect to $\bar{T}(0.8 \leq S(\bar{T}) \leq 1.2)$ for a given nucleation temperature $T_{0}$. The results and conclusions presented below, including the analytical derivation in Sect. 5.1, do not depend on the choice of $\bar{T}$. The only requirement for $\bar{T}$ is that it is sufficiently low to allow for nucleation along the temperature time series, specifically $\bar{T}+T^{\prime}(t)<T_{0}$ for at least some time $(t)$ in the time series.

\subsection{Constant vertical velocity}

Here temperature is set to decrease with time due to adiabatic cooling at a constant vertical velocity in a hydrostatic background, i.e.

$T^{\prime}(t)=-\frac{g}{c_{p}} w t$

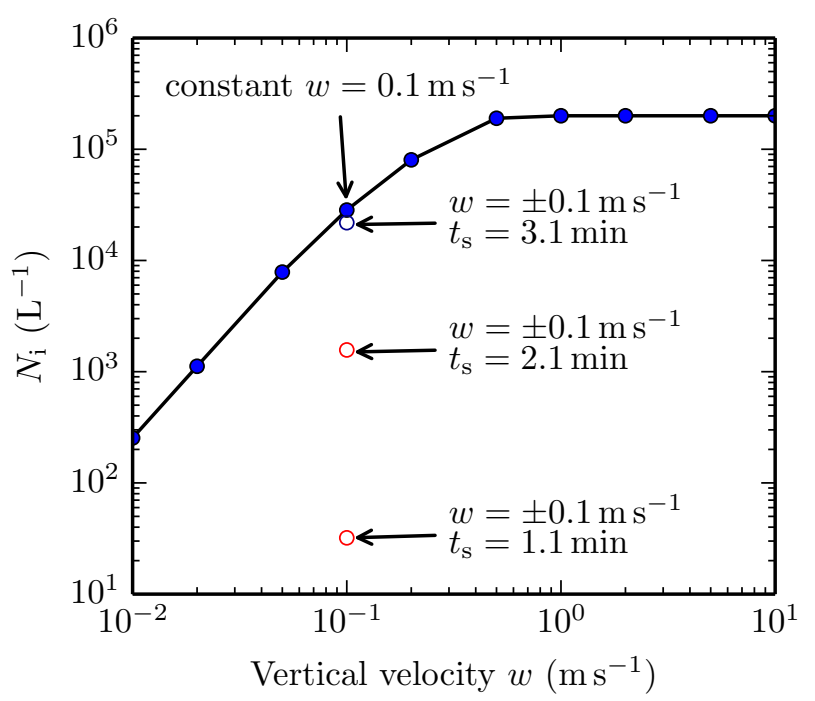

Figure 4. INCs obtained for $\alpha=0.1$ with constant $w$ (filled circles), and with $w= \pm 0.1 \mathrm{~m} \mathrm{~s}^{-1}$ (open circles), see Eq. (7). Vapour-limit events are shown in blue and temperature-limit events are shown in red.

For $\alpha=0.1$, the number of ice crystals nucleated $N_{\mathrm{i}}$ increases with $w$ if $w<1 \mathrm{~m} \mathrm{~s}^{-1}$ (see Fig. 4). For $w \geq 1 \mathrm{~m} \mathrm{~s}^{-1}$, all aerosols particles form ice, hence $N_{\mathrm{i}}=N_{\mathrm{a}}=200 \mathrm{~cm}^{-3}$. Figure 4 shows that if the vertical velocity and the cooling rate are constant during the nucleation events, $w$ must be less than $0.01 \mathrm{~m} \mathrm{~s}^{-1}$ in order for $N_{\mathrm{i}}<100 \mathrm{~L}^{-1}$. This result is consistent with previous studies (e.g. Krämer et al., 2009) of homogeneous freezing under constant vertical velocity.

\subsection{Nonpersistent cooling}

Now we vary $w$ with time so that the rate of change of temperature $\frac{\mathrm{d} T}{\mathrm{~d} t}$ is no longer constant with time. Specifically, we set

$w(t)=\left\{\begin{array}{ll}+0.1 \mathrm{~ms}^{-1} & \text { if } t-t_{0} \leq t_{\mathrm{s}} \\ -0.1 \mathrm{~ms}^{-1} & \text { if } t-t_{0}>t_{\mathrm{S}}\end{array}\right.$.

The time $t_{\mathrm{s}}$ at which $w$ switches signs is varied by setting $t_{\mathrm{S}}=\{1.10 ; 2.10 ; 3.10\}$ min. The dash lines in Fig. 5 show the evolution of the vertical velocity, temperature, saturation ratio, and INC during the nucleation events forced by $w=$ $\pm 0.1 \mathrm{~m} \mathrm{~s}^{-1}$ as defined above.

In the event where $w$ switches signs at $t_{\mathrm{s}}=3.10 \mathrm{~min}$ (blue dash curves in Fig. 5), the saturation ratio $(S)$ reaches a maximum $\left(S_{\max }\right)$ at $t^{*}=3.05 \mathrm{~min}$, which is before the minimum temperature $\left(T_{\min }\right)$ is reached $\left(t^{*}<t_{\mathrm{s}}\right)$. Here, $S_{\max }$ is controlled by the depletion of water vapour by depositional growth of ice crystals. The INC in this event is almost the same as that which would have been obtained if $w$ were kept constant at $0.1 \mathrm{~m} \mathrm{~s}^{-1}$ (see also Fig. 4). We refer to this event and all cases with constant $w$ as "vapour limit", indicating that $N_{\mathrm{i}}$ is limited by the depletion of water vapour. 

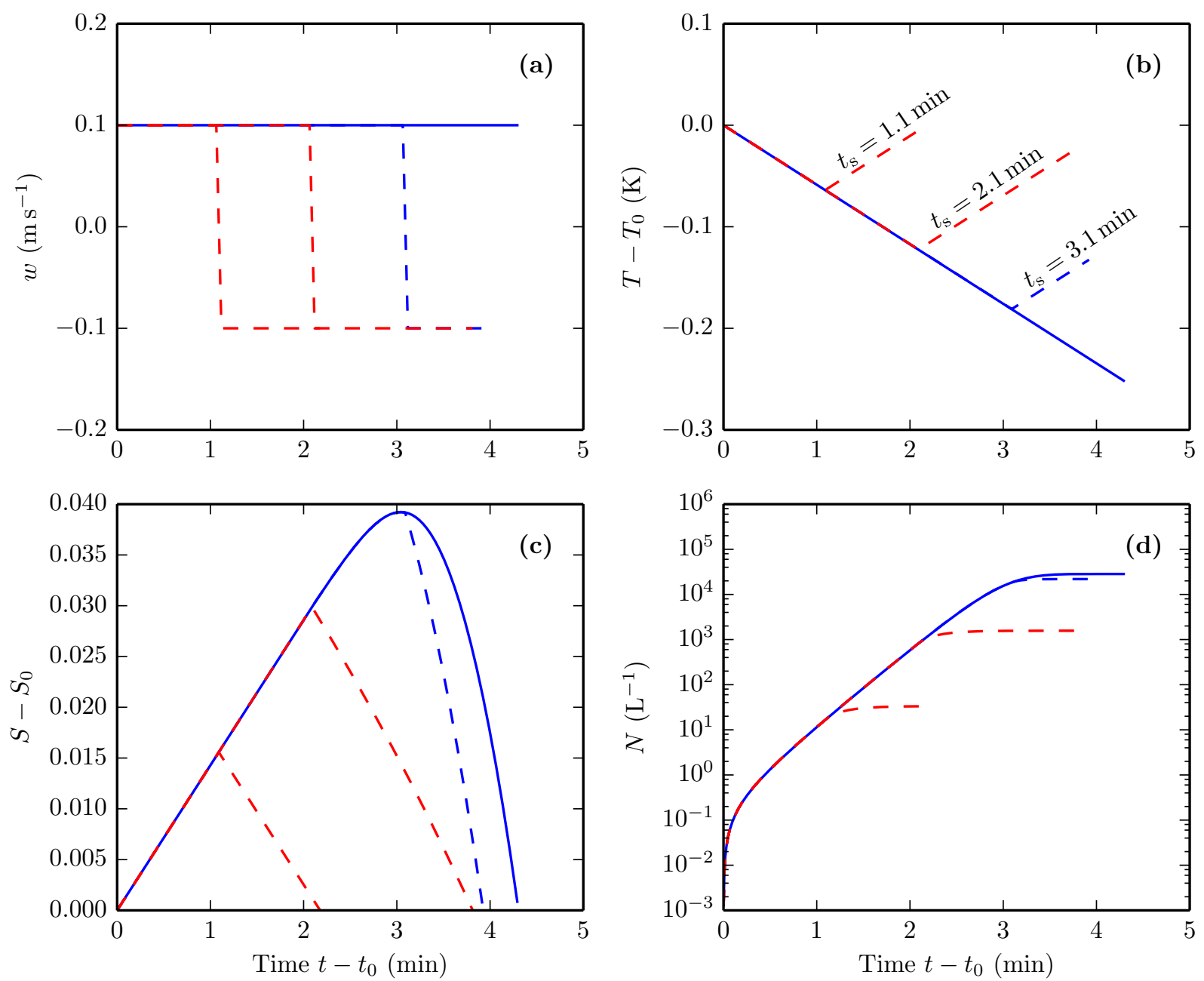

Figure 5. Evolution of vertical velocity (a), temperature (b), saturation ratio (c), and INC (d) during nucleation events forced by constant $w=0.1 \mathrm{~m} \mathrm{~s}^{-1}$ (solid) and by $w= \pm 0.1 \mathrm{~m} \mathrm{~s}^{-1}$ (dash) as defined by Eq. (7). Blue curves show vapour-limit events and red curves show temperature-limit events.

For the other two events in which $w$ switches signs earlier at $t_{\mathrm{S}}=1.10$ and $2.10 \mathrm{~min}$ (red curves in Fig. 5 and red circles in Fig. 4), $N_{\mathrm{i}}$ is significantly smaller than that obtained for the vapour-limit event described above. For these two events, $S_{\max }$ and $T_{\min }$ occur at the same time $\left(t^{*}=t_{\mathrm{s}}\right)$. After $S_{\max }$ is reached, $S$ decreases with time because temperature increases with time. We refer to these events as "temperature limit" because the minimum temperature determines $S_{\max }$ and hence $N_{\mathrm{i}}$. The depletion of water vapour by ice depositional growth can be neglected because $N_{\mathrm{i}}$ is small.

The numerical results show that homogeneous nucleation may be cut off if the cooling that initiates nucleation does not persist sufficiently long into the nucleation events. As a consequence, low INCs can be obtained for temperature-limit events despite initially high vertical velocities and cooling rates. The results in this section are consistent with the simulations with similar setups that have been carried out previously by Spichtinger and Krämer (2013).

\subsection{Balloon temperature time series}

In contrast to the previous sections which used theoretically constructed temperature time series, the numerical simulations presented in this section were carried out using the balloon data. Below, for Sect. 4.3.1 we use $T_{0}=195 \mathrm{~K}$ and $\alpha=$ 0.1 (same as previously in Sect. 4.1 and 4.2). In Sect. 4.3.2 and 4.3.3, we vary $T_{0}$ between 180 and $210 \mathrm{~K}$ and $\alpha$ between 0.001 and 1 to explore sensitivities to these parameters.

\subsubsection{Control simulations with $T_{0}=195 \mathrm{~K}$ and $\alpha=0.1$}

The evolution of the vertical velocity, temperature, saturation ratio, and INC for representative nucleation events simulated using the balloon data is shown in Fig. 6. The plots in the figure are shown for an extended period of time before nucleation begins at $t_{0}$ to illustrate the background condition 

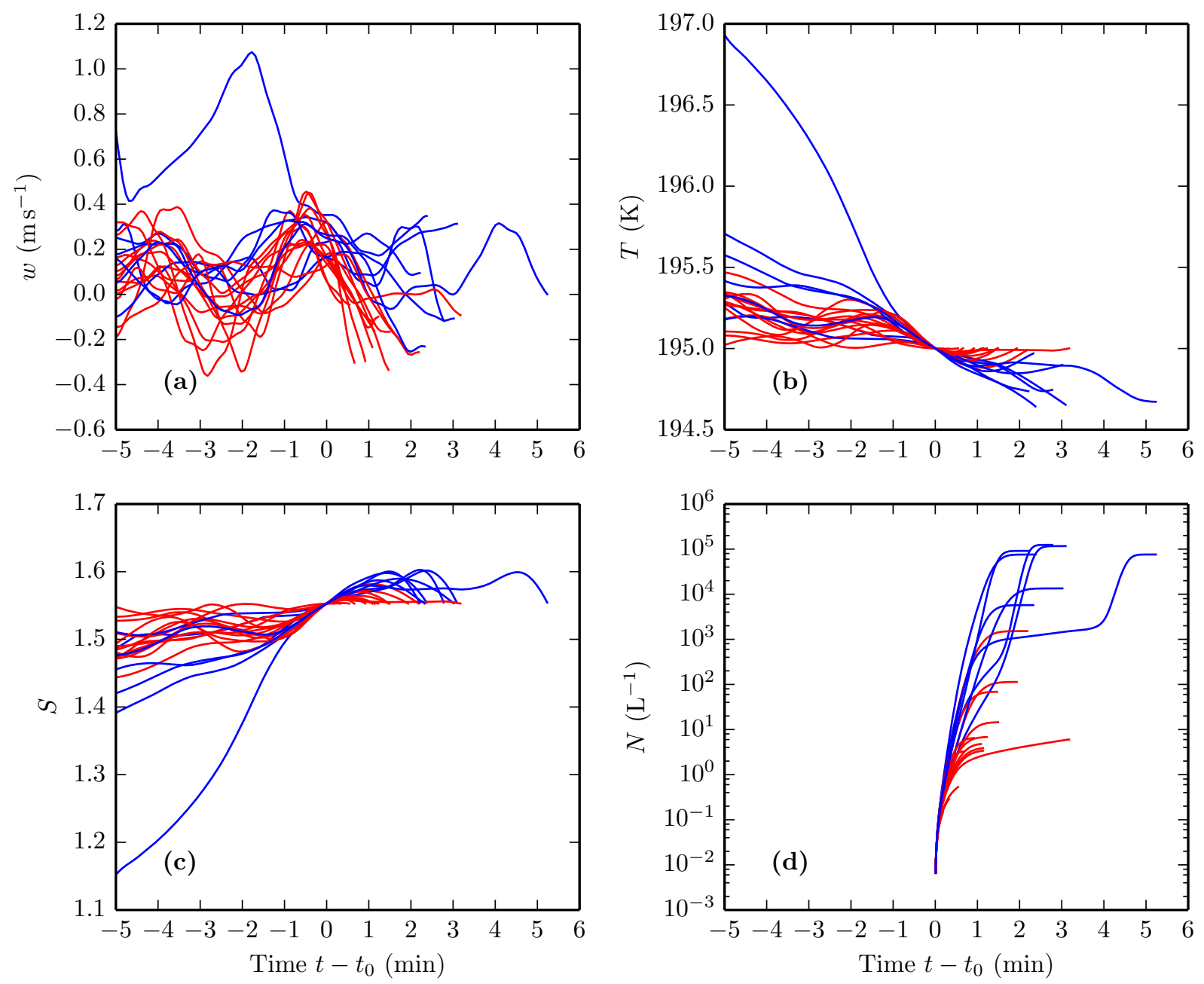

Figure 6. Evolution of vertical velocity (a), temperature (b), saturation ratio (c), and INC (d) in the period immediately before and during representative nucleation events forced by the temperature perturbations derived from the balloon data. The plots are shown for an extended period of time before nucleation begins at $t_{0}$ to illustrate the background condition leading to nucleation. Blue curves show vapour-limit events and red curves show temperature-limit events.

leading to nucleation. However, we will show below that the INC obtained by nucleation is independent of the background condition prior to nucleation.

Figure 6 shows that the duration $\tau$ of the nucleation events (as formally defined by the period during which $J \geq J_{\varepsilon}$ ) is typically less than $5 \mathrm{~min}$. However, during this short time period, the cooling rate is typically not constant because there are high-frequency fluctuations in the observed vertical velocity and temperature time series. Moreover, more than one local maximum and minimum in $T$ and $S$ may occur during one nucleation event. Nevertheless, it is possible to distinguish between

- vapour-limit events, for which the absolute maximum $S_{\max }$ is obtained before the absolute minimum $T_{\min }$ because of substantial vapour depletion - constant cooling rate is a special case of this type; and
- temperature-limit events, for which $S_{\max }$ is obtained at the same time as $T_{\min }$; i.e. temperature controls the cutoff of nucleation, and vapour depletion is negligible.

As shown in Fig. 7, the INCs nucleated during temperature-limit events are typically smaller than for vapour-limit events. The numerical results suggest that, for all nucleation events, $N_{\mathrm{i}}$ increases exponentially with the difference

$\triangle S \equiv S_{\max }-S_{0}$

as long as $N_{\mathrm{i}} \ll N_{\mathrm{a}}$ (Fig. 7). For temperature-limit nucleation events, $N_{\mathrm{i}}$ increases exponentially with $|\triangle T|$, where

$\triangle T \equiv T_{\min }-T_{0}$.

In Sect. 5.1, we will prove analytically that the INC obtained by nucleation $\left(N_{\mathrm{i}}\right)$ is indeed a function of $\triangle S$ (or a func- 

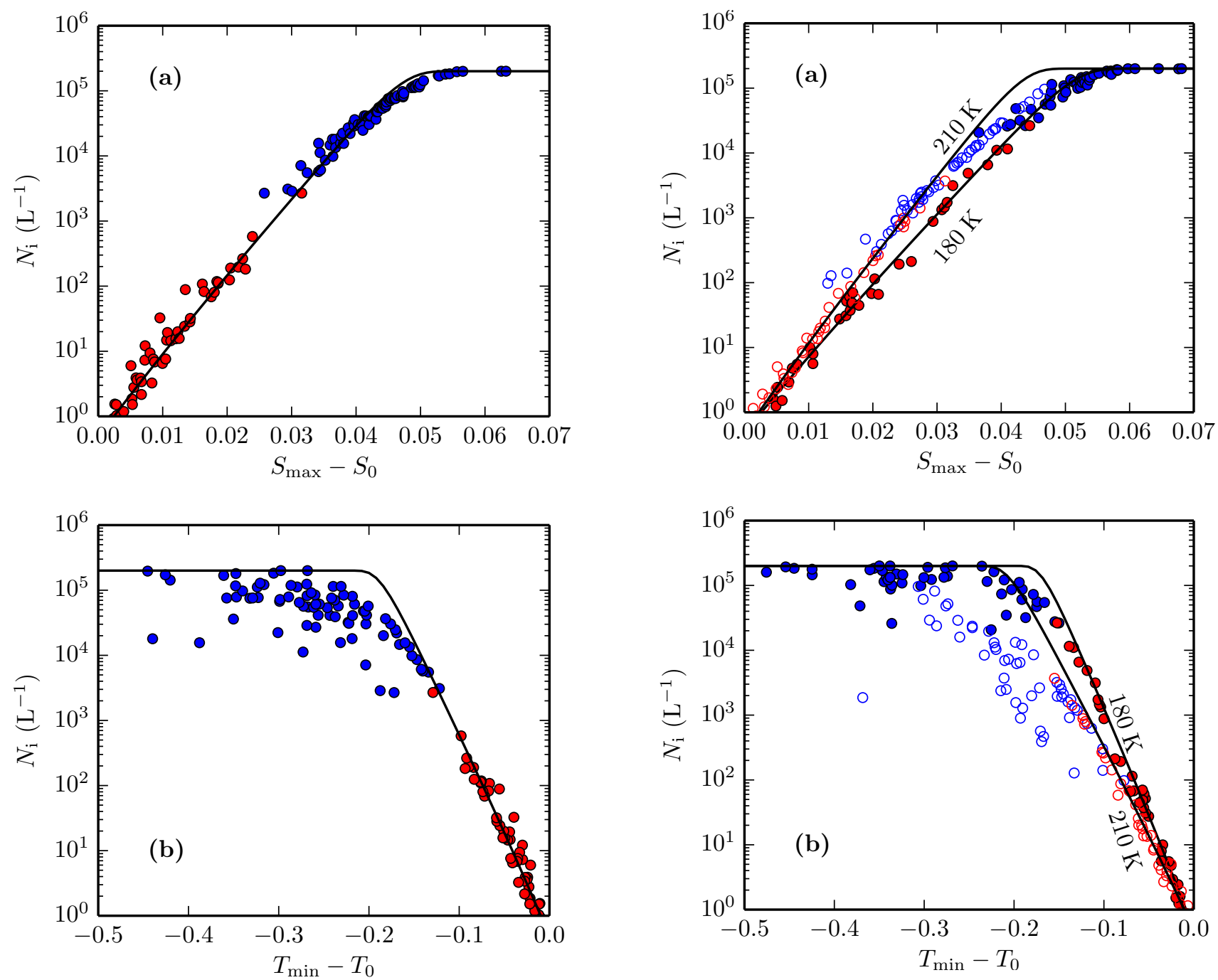

Figure 7. Number of ice crystals nucleated at $T_{0}=195 \mathrm{~K}$ for $\alpha=0.1$ using the balloon temperature perturbation time series. Blue circles show vapour-limit nucleation events. Red circles show temperature-limit nucleation events. The solid curves are obtained from Eqs. (14)-(18) with $\mu=0.05 \mathrm{~s}^{-1}$.

tion of $\Delta T$ for temperature-limit events). These two quantities $(\triangle S$ and $\triangle T)$ are characterisation of the fluctuations in water vapour and temperature during nucleation; they are defined exclusively within the period of nucleation and are independent of the background condition prior to nucleation.

\subsubsection{Sensitivity of INC to nucleation temperature}

Here, we prescribe the initial vapour content $r_{0}$ of the air parcels such that the nucleation temperature $T_{0}$ is either 180 or $210 \mathrm{~K}$. In Fig. 3, this is equivalent to choosing another isoline of $r$ and displacing accordingly the values of $T_{0}$ and $S_{0}$ at nucleation.

The number of ice crystals nucleated for $T_{0}=180$ and $210 \mathrm{~K}$ is shown in Fig. 8. The data for $T_{0}=195 \mathrm{~K}$ shown

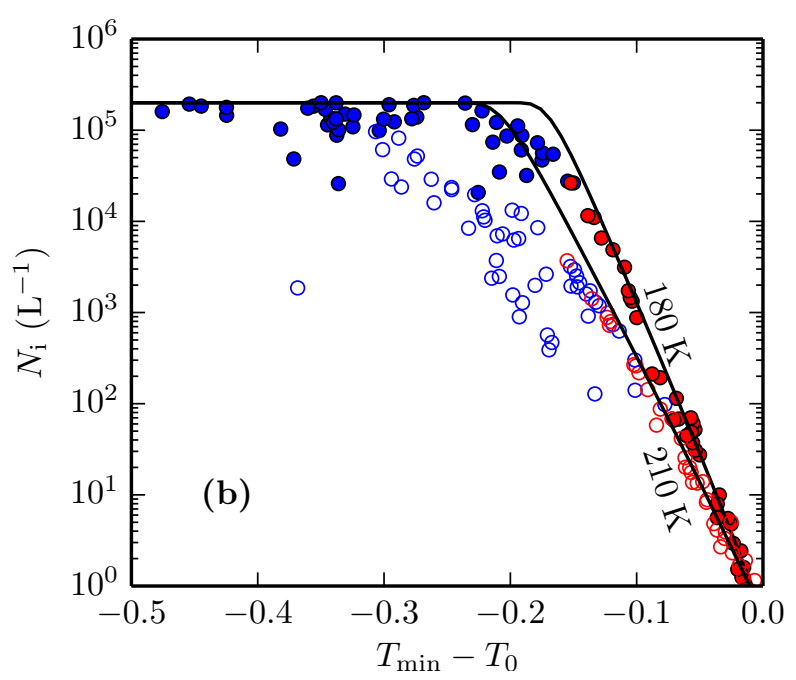

Figure 8. Same as Fig. $7(\alpha=0.1)$ but for $T_{0}=180 \mathrm{~K}$ (filled circles) and $210 \mathrm{~K}$ (empty circles).

previously in Fig. 7 generally lie between the data points for $T_{0}=180$ and $210 \mathrm{~K}$; that is, there is a monotonic relationship between $N_{\mathrm{i}}$ and $T_{0}$. For the same $\triangle S, N_{\mathrm{i}}$ is smaller for smaller $T_{0}$. Conversely, for the same $\triangle T, N_{\mathrm{i}}$ is smaller for larger $T_{0}$.

\subsubsection{Sensitivity of INC to deposition coefficient}

The number of ice crystals nucleated at $T_{0}=195 \mathrm{~K}$ for $\alpha=$ 0.001 and $\alpha=1$ is shown in Fig. 9. Notice that the transition from temperature-limit events to vapour-limit events occurs at lower INC for $\alpha=1$ than $\alpha=0.001$. This makes sense because ice crystals deplete water vapour at a faster rate in the case $\alpha=1$, and so the number of ice crystals needed to significantly deplete water vapour is smaller.

For temperature-limit events, the functional dependence of $N_{\mathrm{i}}$ on $\triangle S$ (or $\triangle T$ ) is invariant for different values of $\alpha$, i.e. $N_{\mathrm{i}}$ is independent of $\alpha$. However, for vapour-limit events, $N_{\mathrm{i}}$ is 
smaller for $\alpha=1$ than $\alpha=0.001$ for the same $\Delta S$ (or $\Delta T$ ). The sensitivity of vapour-limit events to the deposition coefficient is explained in the theory section below.

\section{Theory and discussions}

In this section we provide the theoretical basis that explains the numerical results shown previously in Sect. 4.

\subsection{Formula for ice number concentration}

The rate of nucleation of ice crystals during a nucleation event is given by

$\frac{\mathrm{d} N}{\mathrm{~d} t}=\left(N_{\mathrm{a}}-N\right) J V_{\mathrm{a}}$,

where $N_{\mathrm{a}}$ is the aerosol particle number concentration, $V_{\mathrm{a}}$ is the volume of each aerosol particle, and $J$ is the homogeneous nucleation rate given by Koop et al. (2000, their Eq. 7). By integrating Eq. (10) from the beginning $\left(t=t_{0}\right)$ to end $\left(t=t_{0}+\tau\right)$ of the nucleation event we obtain

$$
\begin{aligned}
\ln \left(1-\frac{N_{\mathrm{i}}}{N_{\mathrm{a}}}\right) & =-V_{\mathrm{a}} \int_{t_{0}}^{t_{0}+\tau} J \mathrm{~d} t \\
& =-V_{\mathrm{a}} J_{\max } \int_{t_{0}}^{t_{0}+\tau} \exp \left(\ln (J)-\ln \left(J_{\max }\right)\right) \mathrm{d} t,
\end{aligned}
$$

where $J_{\max } \equiv J\left(t^{*}\right)$ is the maximum value of $J$ during the nucleation event $\left(t_{0}<t^{*}<t_{0}+\tau\right)$, and $N_{\mathrm{i}} \equiv N\left(t_{0}+\tau\right)$ is the INC obtained at the end of the nucleation event. Following the steepest descent method, we obtain

$$
\begin{aligned}
& \ln \left(1-\frac{N_{\mathrm{i}}}{N_{\mathrm{a}}}\right) \\
& \approx-V_{\mathrm{a}} J_{\max } \int_{t_{0}}^{t_{0}+\tau} \exp \left(\frac{1}{2} \frac{\mathrm{d}^{2}(\ln J)}{\mathrm{d} t^{2}}\left(t^{*}\right)\left(t-t^{*}\right)^{2}\right) \mathrm{d} t \\
& \approx-V_{\mathrm{a}} J_{\max } \int_{t_{0}-t^{*}}^{t_{0}+\tau-t^{*}} \exp \left(-\mu^{2} t^{2}\right) \mathrm{d} t \\
& \approx-V_{\mathrm{a}} J_{\max } \int_{-\infty}^{\infty} \exp \left(-\mu^{2} t^{2}\right) \mathrm{d} t \\
& \approx \sqrt{\pi} V_{\mathrm{a}} \frac{J_{\max }}{\mu}
\end{aligned}
$$

where

$$
\mu^{2}=-\frac{1}{2} \frac{\mathrm{d}^{2}(\ln J)}{\mathrm{d} t^{2}}\left(t^{*}\right)=-\frac{1}{2 J_{\max }} \frac{\mathrm{d}^{2} J}{\mathrm{~d} t^{2}}\left(t^{*}\right) .
$$
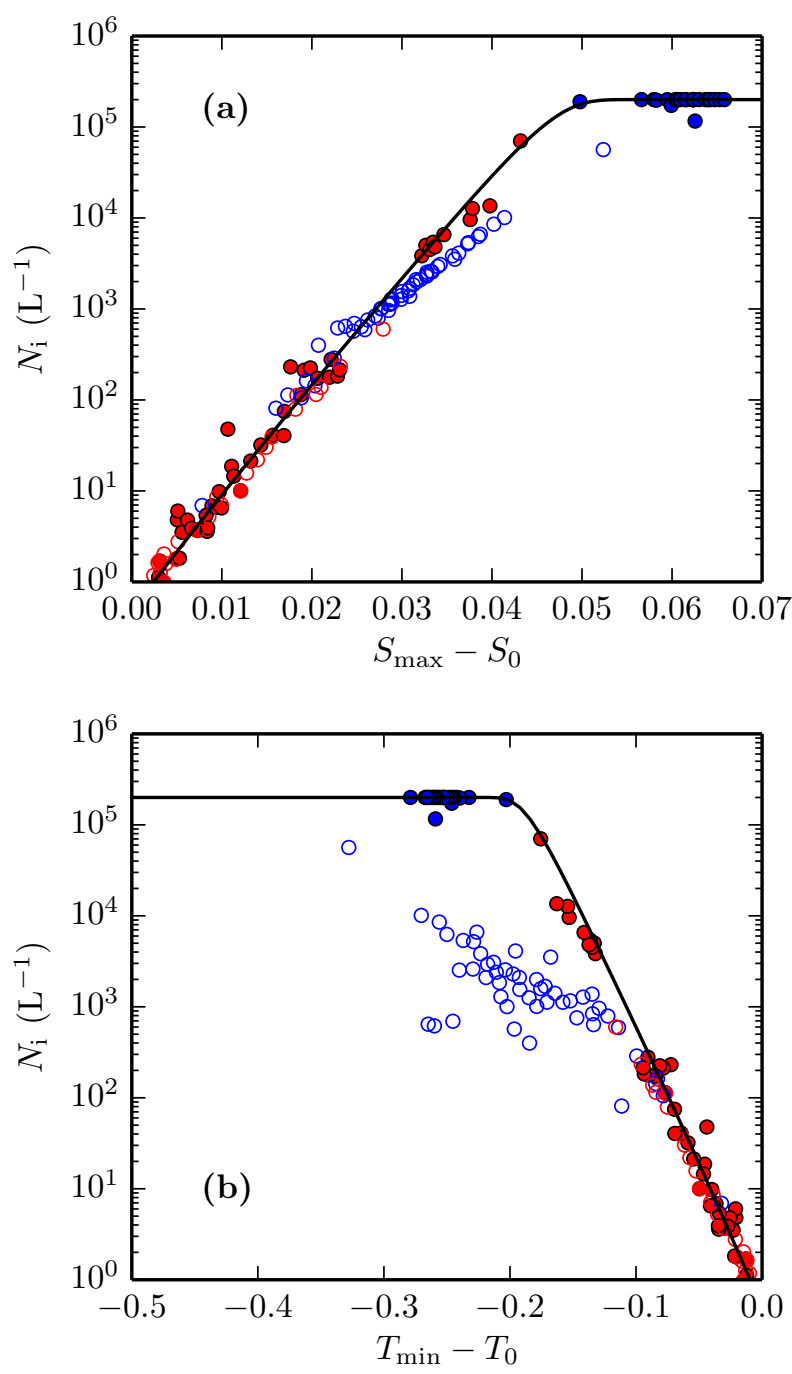

Figure 9. Same as Fig. $7\left(T_{0}=195 \mathrm{~K}\right)$ but for $\alpha=0.001$ (filled circles) and $\alpha=1$ (empty circles).

The approximations used to derive Eq. (12) are appropriate if $t^{*}-t_{0}$ and $t_{0}+\tau-t^{*}$ are both significantly larger than the e-folding timescale given by $\mu^{-1}$. These criteria are well satisfied in our simulations. From Eq. (12) we obtain

$N_{\mathrm{i}} \approx N_{\mathrm{a}}\left(1-\exp \left(-\sqrt{\pi} V_{\mathrm{a}} \frac{J_{\max }}{\mu}\right)\right)$.

For homogeneous ice nucleation, $J$ is given by (see Koop et al., 2000)

$\log _{10}(J)=P_{3}\left((S-1) a_{\mathrm{w}}^{\mathrm{i}}\right)$,

where $P_{3}$ denotes a third-order polynomial, and $a_{\mathrm{w}}^{\mathrm{i}}$ is the water activity of a solution in equilibrium with ice, which is independent of the nature of the solute (Koop et al., 2000). It 
follows that

$$
\begin{aligned}
\log _{10}\left(J_{\max }\right) & =P_{3}\left(\left(S_{\max }-1\right) a_{\mathrm{w}}^{\mathrm{i}}\left(T\left(t^{*}\right)\right)\right) \\
& \approx P_{3}\left(\left(S_{0}+\triangle S-1\right) a_{\mathrm{w}}^{\mathrm{i}}\left(T_{0}\right)\right),
\end{aligned}
$$

where $\triangle S$ is the change in the saturation ratio during the nucleation event defined in Eq. (8). Since $a_{\mathrm{w}}^{\mathrm{i}}$ and $S_{0}$ are both functions of temperature, $J_{\max }$ is a function of $\triangle S$ and temperature. Therefore, Eqs. (14) and (16) indicate that $N_{\mathrm{i}}$ is a function of $\triangle S, \mu$, and temperature. However, note that $\triangle S, \mu$, and temperature are not exclusively independent variables. In fact, substituting Eqs. (15) and (16) into Eq. (13) we obtain

$\mu^{2} \approx f\left(\triangle S, T_{0}\right)\left(\frac{\mathrm{d}^{2} S}{\mathrm{~d} t^{2}}\left(t^{*}\right)\right)+h\left(\triangle S, T_{0}\right)\left(\frac{\mathrm{d}^{2} T}{\mathrm{~d} t^{2}}\left(t^{*}\right)\right)$,

where $f\left(\triangle S, T_{0}\right)$ and $h\left(\triangle S, T_{0}\right)$ are functions of $\triangle S$ and $T_{0}$, and we have made the approximation that $T \approx T_{0}$ because the perturbation $T^{\prime}$ is small compared with $T$ and $T_{0}$. Equation (17) indicates that $\mu$ is a function of $\triangle S, T_{0}$, and the second-order time derivatives of $S$ and $T$ evaluated at $t^{*}$.

For the nucleation events at $T_{0}=195 \mathrm{~K}$ shown in Fig. 7, our calculations indicate that $0.01<\mu<0.1 \mathrm{~s}^{-1}$. From Eq. (14) we deduce that the large range of $N_{\mathrm{i}}\left(10^{-3}\right.$ to $10^{6} \mathrm{~L}^{-1}$ ) obtained for these nucleation events must be due to a large range in $J_{\max }$. If the differences in $\mu$ among the nucleation events can be ignored, at a chosen temperature $N_{\mathrm{i}}$ depends solely on $J_{\max }$, which depends solely on $\triangle S$. In fact, setting $\mu=0.05 \mathrm{~s}^{-1}$ and $T_{0}=195 \mathrm{~K}$ in Eqs. (14) and (16) we obtain a functional dependence of $N_{\mathrm{i}}$ on $\triangle S$ (the solid curve in Fig. 7a) that fits the numerical data well. The error that results from assuming constant $\mu$ is further discussed in Sect. 5.2.

For the special case of a temperature-limit event, the partial pressure of water vapour can be approximated as constant during the nucleation event for $t_{0}<t<t_{0}+\tau$, and so

$\triangle S \approx-\frac{S_{0} L_{\mathrm{s}}}{R_{\mathrm{v}} T_{0}^{2}} \triangle T$,

where $\Delta T$ is the change in temperature during the nucleation event defined in Eq. (9), $L_{\mathrm{S}}$ is the latent heat of sublimation, and $R_{\mathrm{V}}$ is the gas constant of water vapour. With $\mu=0.05 \mathrm{~s}^{-1}$ and $T_{0}=195 \mathrm{~K}$, from Eqs. (14)-(18) we obtain the solid curve in Fig. $7 \mathrm{~b}$ that captures the dependence of $N_{\mathrm{i}}$ on $\Delta T$ as suggested by the simulations of temperature-limit events.

\subsection{Sensitivity of INC to nucleation temperature and deposition coefficient}

Using the formulae derived in Sect. 5.1 we can now explain the sensitivity of the numerical results to $T_{0}$ and the deposition coefficient $\alpha$. The analytic functions of $N_{\mathrm{i}}$-versus- $\triangle S$ and $N_{\mathrm{i}}$-versus- $\triangle T$ vary with $T_{0}$ (because $a_{\mathrm{w}}^{\mathrm{i}}$ depends on $T_{0}$, recall Eq. 16). If $\mu$ is assumed constant, the analytic functions are independent of the deposition coefficient $\alpha$. As described further below, the assumption of constant $\mu$ gives consistent result with the numerical data for temperaturelimit events but tends to overestimate INCs for vapour-limit events at larger $T_{0}$ and/or larger $\alpha$.

For $\alpha=0.1$, Fig. 8a shows that the analytic function of $N_{\mathrm{i}}$-versus- $\triangle S$ is consistent with the numerical data, except for vapour-limit events at $T_{0}=210 \mathrm{~K}$ that produce more than $10^{4} \mathrm{~L}^{-1}$ ice crystals. This error arises because $\mu$ has been assumed to be constant $\left(\mu=0.05 \mathrm{~s}^{-1}\right)$ and independent of $\triangle S$ in the calculation of the analytic curve. The error is larger for larger temperature.

For $\alpha=1$, the analytic function of $N_{\mathrm{i}}$-versus- $\triangle S$ also overestimates $N_{\mathrm{i}}$ for vapour-limit events (Fig. 9a). We again attribute this error to the assumption that $\mu$ is constant over the shown range of $\triangle S$. The deposition coefficient governs the growth rate of ice crystals and affects how the saturation ratio changes with time and how $\mu$ changes with $\triangle S$ (a consequence of Eq. 17). Our calculation indicates that the rate of change of $\mu$ with respect to $\Delta S$ increases with $\alpha$. For larger values of $\alpha$, calculation of $N_{\mathrm{i}}$ (especially for vapour-limit events) must account for the variations in $\mu$ as $\triangle S$ varies.

Let us now study the variation of $N_{\mathrm{i}}$ with respect to $\triangle T$ (Figs. 8b and 9b). Recall that the function of $N_{\mathrm{i}}$ with respect to $\triangle T$ is derived by neglecting the depletion of water vapour due to ice depositional growth (see Eq. 18). For all values of $T_{0}$ and $\alpha$ tested here, the analytic function with constant $\mu$ explains well the pattern of $N_{\mathrm{i}}$-versus- $\triangle T$ for temperaturelimit events. For vapour-limit events, the analytic curves in Figs. $8 \mathrm{~b}$ and $9 \mathrm{~b}$ overestimate the numerical solution because of (i) the neglect of water vapour depletion in Eq. (18) and (ii) the assumption of constant $\mu$.

\subsection{Dependence of INC on the initial water vapour mixing ratio}

The temperature time series $T(t)$ along the trajectory of an air parcel (recall Eq. 5) and the initial water vapour content $r_{0}$ of the parcel are two independent conditions to be specified for the simulations. The initial water vapour content $r_{0}$ has a one-to-one relationship with the temperature at the threshold of nucleation $T_{0}$ via Eq. (4). In Sect. 4 we have studied how the INC varies with the various forms of $T(t)$ for a given $r_{0}$ and a corresponding $T_{0}$. Here, however, we discuss how the INC varies as $r_{0}$ and $T_{0}$ vary for a given $T(t)$.

Now, consider air parcels with slightly different initial water vapour mixing ratios: $r_{0}$ and $r_{0}+\delta r_{0}$. The nucleation temperatures for these air parcels are respectively $T_{0}$ and $T_{0}+\delta T_{0}$ (see illustration in Figs. 3 and 10). For constant pressure, $\delta r_{0}$ and $\delta T_{0}$ are related by

$\frac{\delta r_{0}}{r_{0}}=\frac{\delta e_{\mathrm{sat}}}{e_{\mathrm{sat}}}+\frac{1}{S_{0}} \frac{\mathrm{d} S_{0}}{\mathrm{~d} T_{0}} \delta T_{0}=\frac{L_{\mathrm{s}}}{R_{\mathrm{v}} T_{0}^{2}} \delta T_{0}+\frac{1}{S_{0}} \frac{\mathrm{d} S_{0}}{\mathrm{~d} T_{0}} \delta T_{0}$ 

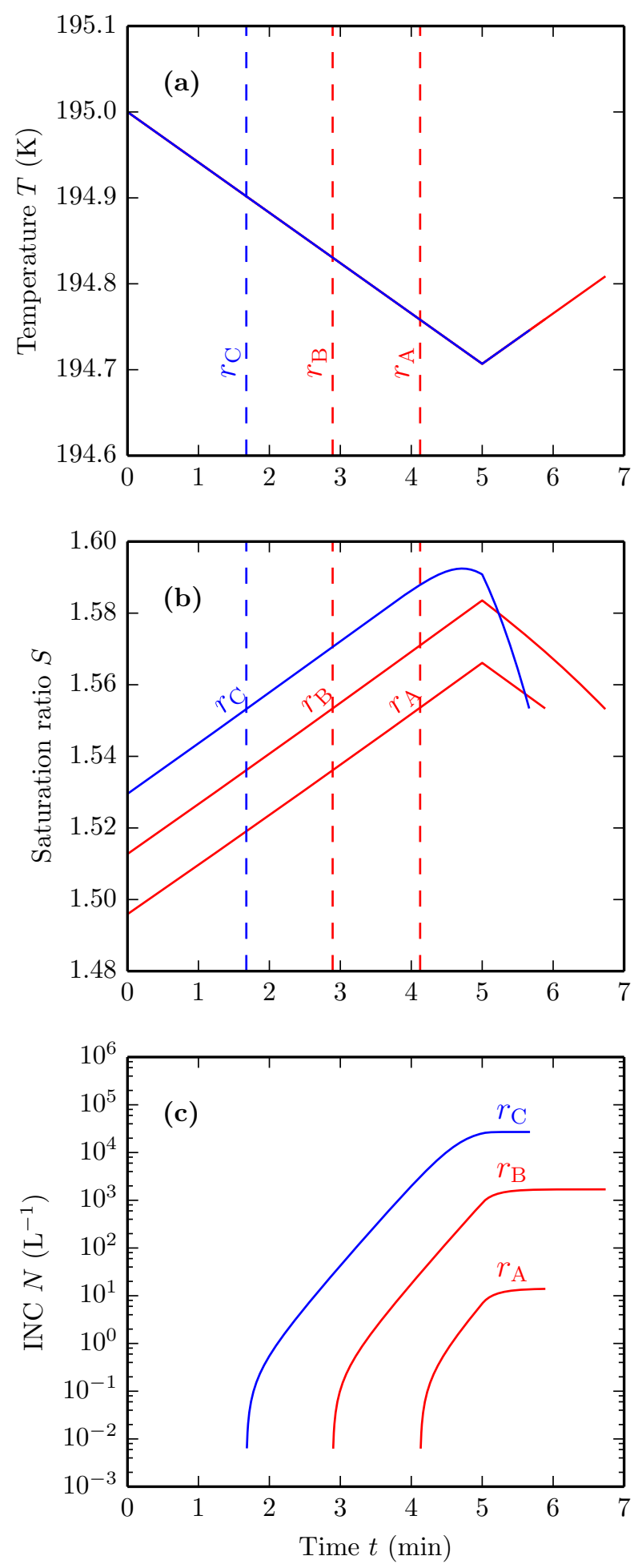

Figure 10. Evolution of temperature (a), saturation ratio (b), and INC (c) for three air parcels with slightly different initial water vapour mixing ratios: $\left\{r_{\mathrm{A}}=1.78 ; r_{\mathrm{B}}=1.80 ; r_{\mathrm{C}}=\right.$ $1.82\} \times 10^{-5} \mathrm{~kg} \mathrm{~kg}^{-1}$. The parcels follow the same temperature time series as shown in (a), but they begin nucleation at different times (indicated by the dash lines) and end up with widely different INCs. by Eq. (4) and the Clausius-Clapeyron relation. The first term dominates the right-hand side of Eq. (19), from which we obtain

$\frac{\mathrm{d} T_{0}}{\mathrm{~d} r_{0}} \approx \frac{R_{\mathrm{v}} T_{0}^{2}}{L_{\mathrm{s}} r_{0}}$,

which indicates that $T_{0}$ increases monotonically with $r_{0}$. For a given temperature time series $T(t)$, the minimum temperature $T_{\min }$ experienced by the parcels is the same (see Fig. 10). It follows that $|\triangle T|=T_{0}-T_{\text {min }}$ increases monotonically with $r_{0}$. For temperature-limit events, $N_{\mathrm{i}}$ increases exponentially with $|\triangle T|$ (recall Fig. 7 and Eq. 18), and so it must increase exponentially with $r_{0}$. As $r_{0}$ increases, $N_{\mathrm{i}}$ increases until reaching a limit above which the nucleation event must be vapour limit (see e.g. Fig. 7). Thus, for a given temperature time series, $r_{0}$ controls $N_{\mathrm{i}}$ and also determines whether the nucleation event is temperature or vapour limit.

For example, consider a temperature time series defined by a cooling rate associated with $w=+0.1 \mathrm{~m} \mathrm{~s}^{-1}$ between $t=0$ and $t_{\mathrm{s}}=5 \mathrm{~min}$, and a warming rate associated with $w=$ $-0.1 \mathrm{~m} \mathrm{~s}^{-1}$ after $t_{\mathrm{s}}$ (see Fig. 10). This temperature time series is similar to the profiles we have studied earlier in Sect. 4.2. Consider three air parcels following this temperature time series, but for which $r_{0}=\{1.78 ; 1.80 ; 1.82\} \times 10^{-5} \mathrm{~kg} \mathrm{~kg}^{-1}$. All three air parcels experience nucleation, and in all cases $T_{\min }=194.71 \mathrm{~K}$ occurs during the nucleation periods. However, our calculations give $T_{0}=\{194.76 ; 194.83 ; 194.90\} \mathrm{K}$ and $N_{\mathrm{i}}=\left\{1.4 \times 10^{1} ; 1.7 \times 10^{3} ; 2.7 \times 10^{4}\right\} \mathrm{L}^{-1}$ respectively for the three parcels. Moreover, the two drier air parcels experience temperature-limit nucleation events (red lines in Fig. 10), whereas the moist air parcel experiences a vapourlimit event (blue line in Fig. 10). As illustrated here, small differences in $r_{0}$ result in many orders of magnitude changes in $N_{\mathrm{i}}$. Such a strong dependence of $N_{\mathrm{i}}$ on $r_{0}$ could explain the large-amplitude, small-scale heterogeneities in the INC as observed in cirrus clouds by Jensen et al. (2013).

\section{Conclusions}

We have simulated homogeneous ice nucleation using temperature time series data collected at high frequency by longduration balloon flights near the tropical tropopause. The simulated nucleation events can be conceptually categorised as either vapour limit or temperature limit. For vapour-limit events, nucleation is limited by the depletion of water vapour. In contrast, for temperature-limit events, nucleation is controlled by the fluctuations in temperature (while the depletion in water vapour is negligible). The INC obtained for temperature-limit events is typically smaller than that obtained for vapour-limit events.

Our calculations of temperature-limit events confirm the finding by Spichtinger and Krämer (2013) that highfrequency fluctuations in temperature may limit the INC obtained by homogeneous freezing. Indeed, a small INC is ob- 
tained if the gravity waves produce large but non-persistent cooling rates such that the absolute drop in temperature (i.e. the difference between the temperature at the threshold of nucleation and the minimum temperature obtained during nucleation) remains small. This relationship between the INC and temperature has been illustrated here both numerically and analytically.

In addition to the fluctuations in temperature, small variations in the initial water vapour content of the air parcels can also lead to large variations in the INC obtained by nucleation. Moreover, post-nucleation processes acting during the cirrus life cycle contribute to modify the cloud original characteristics. Simulations of cirrus clouds in the TTL by Dinh et al. $(2012,2014)$ show that the INC decreases by several orders of magnitude as the cloud ages. For these reasons, we suggest that homogeneous ice nucleation (even acting alone in the absence of heterogeneous freezing) is not inconsistent with recent observations of cirrus clouds in the TTL that indicate generally low but highly variable INC (Jensen et al., 2013).

Finally, it is encouraging that the INC for temperaturelimit events does not depend on the deposition coefficient, a parameter still poorly constrained by theoretical understanding as well as laboratory measurements and field observations.

Acknowledgements. The data used for simulations in this work were collected during the project "Concordiasi," which is supported by the following agencies: Météo-France, CNES, CNRS/INSU, NSF, NCAR, University of Wyoming, Purdue University, University of Colorado, Alfred Wegener Institute, Met Office, and ECMWF. Concordiasi also benefited from the logistic and financial support of the Institut polaire français Paul Emile Victor (IPEV), Programma Nazionale di Ricerche in Antartide (PNRA), United States Antarctic Program (USAP), British Antarctic Survey (BAS), and from measurements by the Baseline Surface Radiation Network (BSRN) at Concordia.

Tra Dinh acknowledges support from the NOAA Climate and Global Change Postdoctoral Fellowship Program and NSF grant AGS-1417659. This collaborative research emerged from Tra Dinh's visit to the Laboratoire de Météorologie Dynamique, which was supported by the "Tropical Cirrus" project of École Polytechnique's "Chaire pour le Développement Durable". Aurélien Podglajen, Albert Hertzog, Bernard Legras, and Riwal Plougonven received support from the ANR project "Stradyvarius" (ANR-13-BS06-0011-01). Additional support was provided by the EU 7th Framework Program under grant 603557 (StratoClim).

The authors would like to thank three anonymous reviewers and Martina Krämer, Bernd Kärcher, and Daniel Knopf for helpful questions and comments that led to significant improvements of this work.

Edited by: M. Krämer

\section{References}

Barahona, D. and Nenes, A.: Parameterization of cirrus cloud formation in large-scale models: Homogeneous nucleation, J. Geophys. Res., 113, D11211, doi:10.1029/2007JD009355, 2008.

Barahona, D. and Nenes, A.: Dynamical states of low temperature cirrus, Atmos. Chem. Phys., 11, 3757-3771, doi:10.5194/acp11-3757-2011, 2011.

Boccara, G., Hertzog, A., Vincent, R. A., and Vial, F.: Estimation of gravity-wave momentum fluxes and phase speeds from quasi-Lagrangian stratospheric balloon flights. Part I: Theory and simulations, J. Atmos. Sci., 65, 3042-3055, doi:10.1175/2008JAS2709.1, 2008.

Brewer, A. W.: Evidence for a world circulation provided by the measurements of helium and water vapour distribution in the stratosphere, Q. J. Roy. Meteorol. Soc., 75, 351-363, doi:10.1002/qj.49707532603, 1949.

Chen, Y., Kreidenweis, S. M., McInnes, L. M., Rogers, D. C., and DeMott, P. J.: Single particle analyses of ice nucleating aerosols in the upper troposphere and lower stratosphere, Geophys. Res. Lett., 25, 1391-1394, doi:10.1029/97GL03261, 1998.

Corti, T., Luo, B. P., Fu, Q., Vömel, H., and Peter, T.: The impact of cirrus clouds on tropical troposphere-to-stratosphere transport, Atmos. Chem. Phys., 6, 2539-2547, doi:10.5194/acp-6-25392006, 2006.

Davis, S., Hlavka, D., Jensen, E., Rosenlof, K., Yang, Q., Schmidt, S., Borrmann, S., Frey, W., Lawson, P., Voemel, H., and Bui, T. P.: In situ and lidar observations of tropopause subvisible cirrus clouds during TC4, J. Geophys. Res., 115, D00J17, doi:10.1029/2009JD013093, 2010.

Dinh, T. and Durran, D. R.: A hybrid bin scheme to solve the condensation/evaporation equation using a cubic distribution function, Atmos. Chem. Phys., 12, 1003-1011, doi:10.5194/acp-121003-2012, 2012.

Dinh, T. and Fueglistaler, S.: Cirrus, Transport, and Mixing in the Tropical Upper Troposphere, J. Atmos. Sci., 71, 1339-1352, doi:10.1175/JAS-D-13-0147.1, 2014a.

Dinh, T. and Fueglistaler, S.: Microphysical, radiative and dynamical impacts of thin cirrus clouds on humidity in the tropical tropopause layer and stratosphere, Geophys. Res. Lett., 41, 6949-6955, doi:10.1002/2014GL061289, 2014b.

Dinh, T., Durran, D. R., and Ackerman, T.: Cirrus and water vapor transport in the tropical tropopause layer - Part 1: A specific case modeling study, Atmos. Chem. Phys., 12, 9799-9815, doi:10.5194/acp-12-9799-2012, 2012.

Dinh, T., Fueglistaler, S., Durran, D., and Ackerman, T.: Cirrus and water vapour transport in the tropical tropopause layer Part 2: Roles of ice nucleation and sedimentation, cloud dynamics, and moisture conditions, Atmos. Chem. Phys., 14, 1222512236, doi:10.5194/acp-14-12225-2014, 2014.

Fueglistaler, S., Dessler, A. E., Dunkerton, T. J., Folkins, I., Fu, Q., and Mote, P. W.: Tropical tropopause layer, Rev. Geophys., 47, RG1004, doi:10.1029/2008RG000267, 2009.

Hermann, M., Zahn, A., Heinrich, G., and Brenninkmeijer, C. A. M.: Meridional distributions of aerosol particle number concentrations in the upper troposphere and lower stratosphere obtained by Civil Aircraft for Regular Investigation of the Atmosphere Based on an Instrument Container (CARIBIC) flights, J. Geophys. Res., 108, 4114, doi:10.1029/2001JD001077, 2003. 
Jensen, E. J., Toon, O. B., Pfister, L., and Selkirk, H. B.: Dehydration of the upper troposphere and lower stratosphere by subvisible cirrus clouds near the tropical tropopause, Geophys. Res. Lett., 23, 825-828, doi:10.1029/96GL00722, 1996.

Jensen, E. J., Pfister, L., Bui, T.-P., Lawson, P., and Baumgardner, D.: Ice nucleation and cloud microphysical properties in tropical tropopause layer cirrus, Atmos. Chem. Phys., 10, 1369-1384, doi:10.5194/acp-10-1369-2010, 2010.

Jensen, E. J., Pfister, L., and Bui, T. P.: Physical processes controlling ice concentrations in cold cirrus near the tropical tropopause, J. Geophys. Res., 117, D11205, doi:10.1029/2011JD017319, 2012.

Jensen, E. J., Diskin, G., Lawson, R. P., Lance, S., Bui, T. P., Hlavka, D., McGill, M., Pfister, L., Toon, O. B., and Gao, R.: Ice nucleation and dehydration in the Tropical Tropopause Layer, P. Natl. Acad. Sci., 110, 2041-2046, doi:10.1073/pnas.1217104110, 2013.

Kärcher, B. and Lohmann, U.: A parameterization of cirrus cloud formation: Homogeneous freezing of supercooled aerosols, J. Geophys. Res., 107, 4010, doi:10.1029/2001JD000470, 2002.

Kärcher, B., Dörnbrack, A., and Sölch, I.: Supersaturation Variability and Cirrus Ice Crystal Size Distributions, J. Atmos. Sci., 71, 2905-2926, doi:10.1175/JAS-D-13-0404.1, 2014.

Koop, T. and Zobrist, B.: Parameterizations for ice nucleation in biological and atmospheric systems, Phys. Chem. Chem. Phys., 11, 10839-10850, doi:10.1039/b914289d, 2009.

Koop, T., Luo, B., Tsias, A., and Peter, T.: Water activity as the determinant for homogeneous ice nucleation in aqueous solutions, Nature, 406, 611-614, doi:10.1038/35020537, 2000.

Krämer, M., Schiller, C., Afchine, A., Bauer, R., Gensch, I., Mangold, A., Schlicht, S., Spelten, N., Sitnikov, N., Borrmann, S., de Reus, M., and Spichtinger, P.: Ice supersaturations and cirrus cloud crystal numbers, Atmos. Chem. Phys., 9, 3505-3522, doi:10.5194/acp-9-3505-2009, 2009.

Lawson, R. P., Pilson, B., Baker, B., Mo, Q., Jensen, E., Pfister, L., and Bui, P.: Aircraft measurements of microphysical properties of subvisible cirrus in the tropical tropopause layer, Atmos. Chem. Phys., 8, 1609-1620, doi:10.5194/acp-8-1609-2008, 2008.

Lohmann, U. and Roeckner, E.: Influence of cirrus cloud radiative forcing on climate and climate sensitivity in a general circulation model, J. Geophys. Res., 100, 16305, doi:10.1029/95JD01383, 1995.

Magee, N., Moyle, A. M., and Lamb, D.: Experimental determination of the deposition coefficient of small cirrus-like ice crystals near -50 Celsius, Geophys. Res. Lett., 33, L17813, doi:10.1029/2006GL026665, 2006.

Massman, W. J.: On the nature of vertical oscillations of constant volume balloons, J. Appl. Meteorol., 17, 1351-1356, doi:10.1175/1520-0450(1978)017<1351:OTNOVO>2.0.CO;2, 1978.
Murphy, D. M.: Rare temperature histories and cirrus ice number density in a parcel and a one-dimensional model, Atmos. Chem. Phys., 14, 13013-13022, doi:10.5194/acp-14-13013-2014, 2014.

Murphy, D. M. and Koop, T.: Review of the vapour pressures of ice and supercooled water for atmospheric applications, Q. J. Roy. Meteorol. Soc., 131, 1539-1565, doi:10.1256/qj.04.94, 2005.

Nastrom, G. D.: The response of superpressure balloons to gravity waves, J. Appl. Meteorol., 19, 1013-1019, doi:10.1175/15200450(1980)019<1013:TROSBT>2.0.CO;2, 1980.

Podglajen, A., Hertzog, A., Plougonven, R., and Žagar, N.: Assessment of the accuracy of (re)analyses in the equatorial lower stratosphere, J. Geophys. Res., 119, 11,166-11,188, doi:10.1002/2014JD021849, 2014.

Pruppacher, H. R. and Klett, J. D.: Microphysics of clouds and precipitation, D. Reidel Publishing Company, Dordrecht, the Netherlands, 1978.

Rabier, F., Bouchard, A., Brun, E., Doerenbecher, A., Guedj, S., Guidard, V., Karbou, F., Peuch, V.-H., Amraoui, L. E., Puech, D., Genthon, C., Picard, G., Town, M., Hertzog, A., Vial, F., Cocquerez, P., Cohn, S. A., Hock, T., Fox, J., Cole, H., Parsons, D., Powers, J., Romberg, K., VanAndel, J., Deshler, T., Mercer, J., Haase, J. S., Avallone, L., Kalnajs, L., and Mechoso, C. R.: The Concordiasi project in Antarctica, B. Am. Meteorol. Soc., 91, 69-86, doi:10.1175/2009bams2764.1, 2010.

Ren, C. and Mackenzie, A. R.: Cirrus parametrization and the role of ice nuclei, Q. J. Roy. Meteorol. Soc., 131, 1585-1605, doi:10.1256/qj.04.126, 2005.

Rogers, D. C., Demott, P. J., Kreidenweis, S. M., and Chen, Y.: Measurements of ice nucleating aerosols during SUCCESS, Geophys. Res. Lett., 25, 1383-1386, doi:10.1029/97GL03478, 1998.

Shi, X., Liu, X., and Zhang, K.: Effects of preexisting ice crystals on cirrus clouds and comparison between different ice nucleation parameterizations with the Community Atmosphere Model (CAM5), Atmos. Chem. Phys., 15, 1503-1520, doi:10.5194/acp-15-1503-2015, 2015.

Skrotzki, J., Connolly, P., Schnaiter, M., Saathoff, H., Möhler, O., Wagner, R., Niemand, M., Ebert, V., and Leisner, T.: The accommodation coefficient of water molecules on ice - cirrus cloud studies at the AIDA simulation chamber, Atmos. Chem. Phys. 13, 4451-4466, doi:10.5194/acp-13-4451-2013, 2013.

Spichtinger, P. and Krämer, M.: Tropical tropopause ice clouds: a dynamic approach to the mystery of low crystal numbers, Atmos. Chem. Phys., 13, 9801-9818, doi:10.5194/acp-13-98012013, 2013.

Vincent, R. A. and Hertzog, A.: The response of superpressure balloons to gravity wave motions, Atmos. Meas. Tech., 7, 10431055, doi:10.5194/amt-7-1043-2014, 2014. 